\title{
Substituição do milho por casca de café ou de soja em dietas para vacas leiteiras: consumo, digestibilidade dos nutrientes, produção e composição do leite ${ }^{1}$
}

\author{
André Soares de Oliveira ${ }^{2}$, José Maurício de Souza Campos ${ }^{3}$, Sebastião de Campos \\ Valadares Filho ${ }^{3}$, Anderson Jorge de Assis ${ }^{4}$, Rafael Monteiro Araújo Teixeira ${ }^{5}$, Rilene \\ Ferreira Diniz Valadares ${ }^{6}$, Douglas dos Santos Pina ${ }^{5}$, Gustavo Soares de Oliveira ${ }^{7}$
}

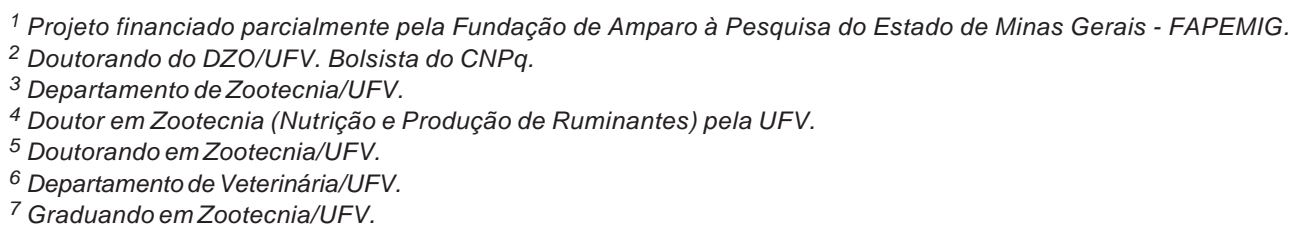

RESUMO - Objetivou-se avaliar o efeito da substituição do milho por casca de café ou casca de soja na dieta sobre o consumo e a digestibilidade dos nutrientes, a produção e composição do leite, a variação de peso corporal e a mobilização de reserva corporal em vacas leiteiras. Foram utilizadas 12 vacas holandesas, puras e mestiças, distribuídas em três quadrados latinos 4 $\times$ 4. As dietas foram isonitrogenadas $(14 \%$ de $\mathrm{PB}$, na MS) e a dieta controle foi composta de $60 \%$ de silagem de milho e $40 \%$ de concentrado na MS. Foram avaliadas três dietas à base de cana-de-açúcar e com $60 \%$ de concentrado na MS: uma controle (sem casca de soja ou de café), uma com $25 \%$ e outra com $50 \%$ de substituição do milho pela casca de café e casca de soja, respectivamente. O consumo de MS não foi afetado pelas dietas e apresentou valor médio de 19,39 kg/dia. Apesar das diferenças nos consumos de PB e NDT, as dietas foram suficientes para atender às exigências para produção de leite de $20 \mathrm{~kg} /$ dia (corrigida ou não para 3,5\% de gordura) e ganho de peso de $0,50 \mathrm{~kg} /$ dia, o que explica a ausência de diferenças na produção de leite corrigida $(20,54 \mathrm{~kg} / \mathrm{dia}) \mathrm{ou}$ não para 3,5\% de gordura $(19,68 \mathrm{~kg} /$ dia $)$, na variação de peso $(0,683 \mathrm{~kg} /$ dia $)$ e nos níveis plasmáticos de ácidos graxos não-esterificados (AGNE) $(226,99 \mu \mathrm{eq} / \mathrm{L})$. A composição do leite não foi afetada pelas dietas, à exceção dos teores de lactose e extrato seco desengordurado. Em dietas à base de cana-de-açúcar para vacas com produção de $20 \mathrm{~kg}$ de leite/dia, o milho pode ser substituído em $25 \%$ pela casca de café ou em $50 \%$ pela casca de soja, desde que a participação de concentrado seja de $60 \%$.

Palavras-chave: AGNE, silagem de milho, subprodutos

\section{Replacing corn with coffee hulls or soyhulls in dairy cows diets: intake, nutrient digestibility, and milk production and composition}

\begin{abstract}
The objectives of this trial were to evaluate the effect of replacing corn meal with coffee hulls or soyhulls on intake and apparent digestibility of nutrients, milk yield and composition, and body weight (BW) change in lactating dairy cows. Twelve purebred and crossbred Holstein cows were assigned to three replicated $4 \times 4$ Latin squares. Diets were isonitrogeneous (14\% of CP, DM basis) and control diet contained $60 \%$ corn silage plus $40 \%$ concentrate. Three sugarcane based diets with $60 \%$ concentrate were used: control (without coffee hulls or soyhulls), $25 \%$ and $50 \%$ replacing corn meal by coffee hulls and soyhulls, respective. Dry matter intake did not differ and averaged $19.39 \mathrm{~kg}$ /day among diets. Although the intakes of $\mathrm{CP}$ and total digestible nutrients differ among treatments, all diets were able to meet the nutrional requirements for milk production, 3.5\% fat-corrected milk (FCM), and BW gain because milk yield, FCM, BW change and plasma concentration of non-esterified fatty acids did not differ and averaged $20.54 \mathrm{~kg} /$ day, $19.68 \mathrm{~kg} / \mathrm{day}, 0.683 \mathrm{~kg} / \mathrm{day}$, and $226.99 \mu$ eq/ $/ \mathrm{across}$ diets, respectively. With the exception of lactose and solids nonfat no other significant differences in milk composition were observed across diets. In sugarcane based diets for cows producing $20 \mathrm{~kg}$ of milk/day, the corn can be replacement by $25 \%$ of coffee hulls or $50 \%$ of soyhulls since the concentrate participation is of $60 \%$.
\end{abstract}

Key Words: by-products, corn silage, NEFA

\section{Introdução}

A cana-de-açúcar tem sido utilizada como recurso forrageiro há décadas por apresentar vantagens como elevada produção de MS por área, disponibilidade no período seco do ano, baixo custo de produção em relação às culturas 
de milho e sorgo e facilidade de cultivo. Além disso, o conhecimento sobre o uso e a correção das deficiências nutricionais dessa forragem permitiu a massificação de sua utilização na alimentação de bovinos de leite.

Entretanto, resultados de estudos têm limitado o uso da cana-de-açúcar para vacas de baixa produção (Castro et al., 1967; Naufel et al., 1969; Nogueira Filho et al., 1977; Biondi et al., 1978; Boin et al., 1983a; Valle et al., 1986; Paiva et al., 1991; Vilela et al., 2003), o que refletiu no uso em maior escala em sistemas de menor potencial de produção individual de leite (Bressan et al., 1999).

Pesquisas recentes com vacas em lactação em sistemas de confinamento total produzindo de 20 a $30 \mathrm{~kg} / \mathrm{dia}$ apontaram reduções no consumo de MS quando a silagem de milho é substituída por cana-de-açúcar em dietas com 40 a $55 \%$ de concentrado, o que ocasiona menor produção de leite e indícios de elevada mobilização de reservas corporais, com potencial para comprometer a eficiência reprodutiva (Valvasori et al., 1995; Magalhães et al., 2004; Corrêa et al., 2003; Souza, 2003; Costa et al., 2005; Mendonça et al., 2004).

Apesar de a quantidade de fibra não diferir entre a canade-açúcar e a silagem de milho (Valadares Filho et al., 2002), a redução de consumo tem sido associada ao maior teor de fibra indigestível e à menor taxa de digestão da fração fibrosa potencialmente digestível, que aumenta o tempo de retenção da digesta no retículo-rúmen e reduz a taxa de passagem pelo trato gastrointestinal (Allen, 2000).

Para eliminar esses efeitos, é necessário aumentar a quantidade de concentrado para níveis próximos de $60 \%$, na MS, em dietas para vacas produzindo de 20 a $25 \mathrm{~kg} / \mathrm{dia}$ de leite (Costa et al., 2005). Como o concentrado tem maior participação no custo de produção de leite em sistemas com rebanhos especializados (Ferreira, 2002), a substituição de fontes energéticas tradicionais, como o milho, por subprodutos da agroindústria pode possibilitar economicamente maiores consumos de concentrado.

Neste contexto, a casca de café e a casca de soja se destacam pela elevada oferta, pelos preços competitivos e pela composição bromatológica, que se adequa à alimentação de ruminantes como substituto de fontes de concentrados energéticos, com a vantagem adicional de não competir com animais não-ruminantes (Teixeira, 1995; Blasi et al., 2000).

Este trabalho foi realizado com o objetivo de avaliar o efeito da substituição do milho por casca de café ou casca de soja em dietas com cana-de-açúcar sobre o consumo e a digestibilidade de nutrientes, a produção e composição do leite e a mobilização de reserva corporal em vacas leiteiras de alta produção.

\section{Material e Métodos}

O experimento foi conduzido na Unidade de Ensino, Pesquisa e Extensão em Gado de Leite (UEPE-GL) do Departamento de Zootecnia (DZO), na Universidade Federal de Viçosa (UFV), no período de junho a setembro de 2003.

Foram utilizadas 12 vacas holandesas, puras e mestiças, distribuídas em três quadrados latinos $4 \times 4$, balanceados de acordo com o período de lactação. Os animais do 1ํㅡㄹ do $2 \underline{\mathrm{o}}$ e do $3 \underline{\mathrm{o}}$ quadrado latino entraram no experimento, em média, com 116, 176 e 211 dias de lactação e todas as vacas apresentaram no final do experimento menos de 150 dias de gestação.

O experimento foi constituído de quatro períodos, cada um com 19 dias de duração, os 12 primeiros de adaptação às dietas e os demais para coleta de dados. Os animais foram alimentados com quatro dietas. A dieta controle foi constituída de silagem de milho (Zea mays, híbrido AG-1051) e $40 \%$ de concentrado, com base na MS, e as dietas à base de cana-de-açúcar (Saccharum officinarum, L; variedade RB 73-9735) foram compostas de $60 \%$ de concentrado, com base na MS, de modo que os percentuais de substituição do milho foram $0 \%, 25 \%$ com casca de café ou $50 \%$ com casca de soja, com base na MS total. A cana-de-açúcar utilizada estava no seu segundo corte, com aproximadamente 10 meses de idade. Para todas as dietas contendo cana-deaçúcar, foi adicionada uma mistura de nove partes de uréia e uma parte de sulfato de amônio (na quantidade de $1 \%$ da dieta, com base na matéria natural), sendo adicionados aos concentrados bicarbonato de sódio e óxido de magnésio na proporção de 2:1.

Os carboidratos totais (CT) foram calculados segundo Sniffen et al. (1992): CT $=100-(\%$ de PB $+\%$ de EE $+\%$ de cinzas). Os carboidratos não-fibrosos (CNF) e carboidratos não-fibrosos corrigidos para cinzas e proteína $\left(\mathrm{CNF}_{\mathrm{cp}}\right)$ foram calculados como proposto por Hall (2000): $\mathrm{CNF}=100-[(\% \mathrm{~PB}$ - \%PB derivada da uréia +\%uréia ) $+\% \mathrm{FDN}+\% \mathrm{EE}+\%$ Cinzas) $] ; \mathrm{CNF}_{\mathrm{cp}}=100-[(\% \mathrm{~PB}-\% \mathrm{~PB}$ derivada da uréia $+\%$ uréia $)$ $+\% \mathrm{FDN}_{\mathrm{cp}}+\% \mathrm{EE}+\%$ Cinzas]. Os nutrientes digestíveis totais (NDT) foram determinados segundo Weiss (1999), pela equação: $\mathrm{NDT}(\%)=\mathrm{PBd}+\mathrm{FDNd}+\mathrm{CNFd}+2,25 \mathrm{EEd}$, em que "d" corresponde ao respectivo nutriente digestível.

Os animais foram manejados em baias individuais, tipo tie stall, onde receberam alimentação ad libitum duas vezes ao dia, às $8 \mathrm{~h}$ e às $17 \mathrm{~h}$. Diariamente, foram feitas amostragens e pesagens das quantidades dos volumosos e dos concentrados fornecidos e das sobras de cada dieta.

As dietas foram formuladas para serem isonitrogenadas, com $14 \%$ de $\mathrm{PB}$, de forma a atender às exigências nutricionais de uma vaca com $580 \mathrm{~kg}$ de peso corporal 
produzindo $20 \mathrm{~kg}$ de leite/dia com $3,5 \%$ de gordura (NRC, 2001) (Tabelas 1, 2 e 3).

O preparo das amostras dos alimentos e das sobras diárias e as análises químico-bromatológicas seguiram as especificações descritas em Silva \& Queiroz (2002). A determinação de nitrogênio não-protéico (NNP) dos alimentos foi realizada segundo Licitra et al. (1996). Determinou-se a atividade ureática da casca de soja pelo método n 20 utilizando-se a variação de $\mathrm{pH}$ como indicador (SINDIRAÇÕES, 1998).

Amostras compostas dos alimentos e das sobras foram enviadas para o Laboratório de Análise de Qualidade do Café, da Empresa de Pesquisa Agropecuária de Minas Gerais, para determinação dos níveis dietéticos e do consumo de cafeína e de polifenóis totais (PFT). Os PFT foram determinados pelo método de Folin Denis (AOAC, 1990) e a cafeína, pela metodologia da AOAC (1990).

A quantidade total de MS fecal excretada foi estimada pela concentração de FDAi, obtida após incubação ruminal dos alimentos, das sobras e das fezes em sacos de poliester (Ankon ${ }^{\circledR}$, filter bag 57) por um período de 144 horas, segundo adaptação de técnica descrita por Cochran et al. (1986). As fezes foram coletadas no $13^{\circ}$ e no $16^{\circ}$ dias de cada período experimental, sempre antes das ordenhas da manhã e da tarde.
As vacas foram ordenhadas, mecanicamente, duas vezes ao dia, procedendo-se ao registro da produção de leite do 13 o ao 19 o dia de cada período experimental. Por meio de dispositivo acoplado à ordenhadeira, coletaram-se amostras de leite $(300 \mathrm{~mL})$ no $16^{0}$ dia, nas ordenhas da manhã e da tarde. As amostras compostas do leite foram acondicionadas em frascos plásticos com conservante $\left(\right.$ Bronopol $\left.^{\circledR}\right)$, mantidas em temperatura de 2 a $6^{\circ} \mathrm{C}$ e encaminhadas para o Laboratório de Análises de Qualidade de Leite, da Embrapa Gado de Leite, para determinação da composição do leite, segundo metodologia descrita pelo International Dairy Federation (1996). A produção de leite corrigida (PLC) para 3,5\% de gordura foi calculada segundo Sklan et al. (1992).

No sétimo dia de adaptação e no final de cada período experimental, foram feitas pesagens individuais dos animais para avaliação da variação de peso. Os pesos dos animais corresponderam às médias de duas pesagens, feitas antes do fornecimento das alimentações e após as ordenhas.

No $16^{\circ}$ dia, foram coletadas amostras de sangue utilizando-se tubos de ensaio com anticoagulante (EDTA). As amostras foram imediatamente centrifugadas a $2.336 \mathrm{x} g$ por 15 minutos para retirada de amostras do plasma para posteior análise de ácidos graxos não-esterificados (AGNE), determinados com o uso de kit comercial (Wako), conforme Jonhson \& Peters (1993).

Tabela 1 - Composição percentual dos ingredientes nas dietas, com base na MS

Table 1 - Ingredient composition of the experimental diets (DM basis)

\begin{tabular}{ll}
\hline Ingrediente & Dieta \\
Ingredient & Diet
\end{tabular}

Silagem de milho (controle) Cana-de-açúcar $+1 \%$ uréia/SA Corn silage Sugarcane $+1 \%$ urea/AS

Cana-de-açúcar Cana-de-açúcar $+\quad$ Cana-de-açúcar + Sugarcane casca de café casca de soja Sugarcane + coffee hulls Sugarcane + soyhulls

Silagem de milho (Corn silage)

Cana-de-açúcar ${ }^{1}$ (Sugarcane)

Fubá de milho (Corn meal)

Casca de café (Coffee hulls)

Casca de soja (Soyhulls)

Farelo de soja (Soybean meal)

Farelo de trigo (Wheat middilings)

Farelo de algodão (Cottonseed meal)

Uréia/SA (9:1) (Urea/AS 9:1)

Tamponantes ${ }^{2}$ (Buffers)

Mistura mineral ${ }^{3}$ (Mineral mix)

Total

\section{0,00}

21,00

8,50

6,54

2, 03

0,60

1,33

100,00
40,00

41,09

$$
\begin{array}{r}
40,00 \\
31,09 \\
10,00 \\
6,60 \\
6,66
\end{array}
$$

6,90

6,29

3, 10

0,85

1,77

100,00

6,60
6,66
3,10
0,85
1,70
100,00

0,85

00,00
40,00

21,09

20,00

3,90

9,56

3,10

0,85

1,50

100,00

${ }^{1}$ Cana-de-açúcar adicionada de 1\% da mistura de uréia mais sulfato de amônio (SA), com base na matéria natural, na proporção de 9:1 (sugarcane plusf 1\% of the mixture of urea plus ammonium sulfate (AS), as fed, in the proportion of 9:1).

$267 \%$ de bicarbonato de sódio e $33 \%$ de óxido de magnésio.

${ }^{3}$ Fosfato bicálcico (dicalcium phosphate): 15,05; 25,75; 29,75; 27,49; calcário calcítico (calcium carbonate): 48,52; 42,10; 38,58; 35,16; sal comum (sodium cloride): 29,$75 ; 23,46 ; 24,88 ; 28,53$; flor de enxofre (sulfur flower): 3,$07 ; 3,04 ; 3,95 ; 5,63$; sulfato de zinco (zinc sulfate): 1,$33 ; 1,00 ; 1,04 ; 1,17$; sulfato de cobre (copper sulfate): 0,$30 ; 0,22 ; 0,23 ; 0,26$; sulfato de manganês (manganese sulfate): 0,$93 ; 0,70 ; 0,73 ; 0,82$; iodato de potássio (potassium iodide): 0,$0077 ; 0,0058 ; 0,0060 ;$ 0,0068; sulfato de cobalto (cobalt sulfate): 0,$0152 ; 0,0114 ; 0,0120 ; 0,0134$; selenito de sódio (sodium selenite): 0,0050; 0,0037; 0,0039; 0,0044; e cloreto de potássio (potassium cloride): 2,93; somente para para dieta cana-de-açúcar (only sugarcane diet). Os valores entre parênteses representam os teores das fontes de minerais na mistura mineral das dietas silagem de milho, cana-de-açúcar, cana-de-açúcar + casca de café e cana-de-açúcar + casca de soja (The values between parentheses represent the sources of minerals in mineral mixture in diets corn silage, sugarcane, sugarcane + coffee hulls and sugarcane + soyhulls). 
Tabela 2 - Composição química dos alimentos utilizados nas dietas experimentais Table 2 - Chemical composition of dietary ingredients

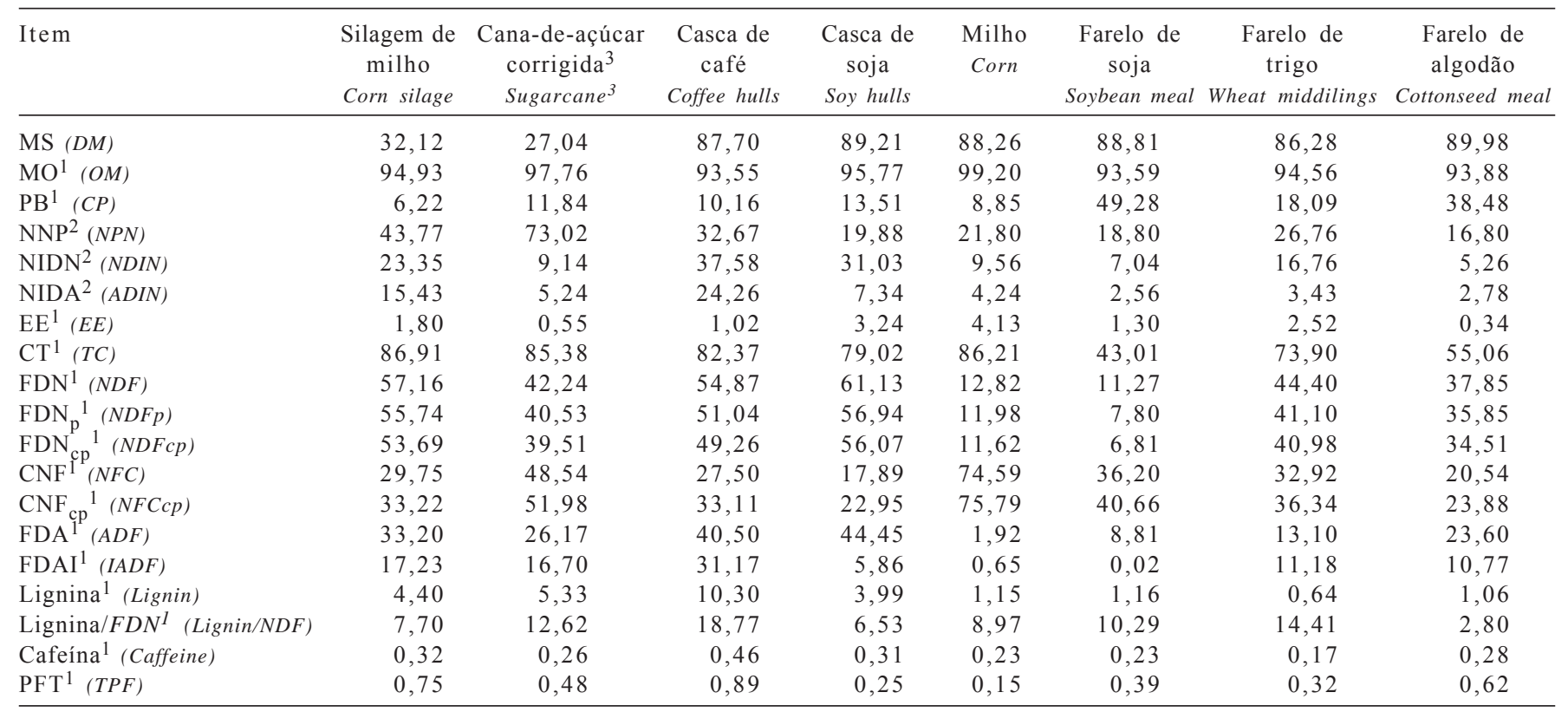

1 Valores em porcentagem da MS [\% of DM].

2 Valores em porcentagem do nitrogênio total (\% of total nitrogen).

3 Correção com $1 \%$ da mistura de uréia + sulfato de amônio $(9: 1)$, com base na matéria natural (sugarcane plus $1 \%$ of the mixture containing urea plus ammonium sulfate), as-fed, in the proportion of 9:1]

Tabela 3 - Composição química das dietas experimentais Table 3 - Chemical composition of the experimental diets

\begin{tabular}{|c|c|c|c|c|}
\hline \multirow[t]{3}{*}{ Item } & \multicolumn{4}{|c|}{$\begin{array}{l}\text { Dieta } \\
\text { Diet }\end{array}$} \\
\hline & \multirow[t]{2}{*}{$\begin{array}{l}\text { Silagem de milho (controle) } \\
\text { Corn silage }\end{array}$} & \multicolumn{3}{|c|}{$\begin{array}{c}\text { Cana-de-açúcar }+1 \% \text { uréia/SA } \\
\text { Sugarcane }+1 \% \text { urea/AS }\end{array}$} \\
\hline & & $\begin{array}{l}\text { Cana-de-açúcar } \\
\text { Sugarcane }\end{array}$ & $\begin{array}{c}\text { Cana-de-açúcar }+ \\
\text { casca de café } \\
\text { Sugarcane }+ \text { coffee hulls }\end{array}$ & $\begin{array}{c}\text { Cana-de-açúcar }+ \\
\text { casca de soja } \\
\text { Sugarcane }+ \text { soyhulls }\end{array}$ \\
\hline $\mathrm{MO}^{1}(\mathrm{OM})$ & 94,31 & 95,61 & 94,94 & 95,32 \\
\hline $\mathrm{PB}^{1}(C P)$ & 13,33 & 14,09 & 14,16 & 14,12 \\
\hline $\mathrm{NNP}^{2} \quad(N P N)$ & 36,38 & 38,18 & 38,91 & 38,25 \\
\hline $\mathrm{NIDN}^{2}$ (NDIN) & 11,77 & 9,02 & 11,06 & 13,77 \\
\hline $\mathrm{NIDA}^{2}$ (ADIN) & 6,16 & 3,99 & 5,41 & 4,74 \\
\hline $\mathrm{EE}^{1}(E E)$ & 2,23 & 2,18 & 1,88 & 1,55 \\
\hline $\mathrm{CT}^{1}(\mathrm{TC})$ & 78,74 & 79,34 & 78,90 & 79,15 \\
\hline $\mathrm{CNF}_{\mathrm{cp}}^{1}(\mathrm{NFCcp})$ & 41,14 & 57,11 & 52,86 & 46,78 \\
\hline $\mathrm{FDA}^{1}(A D F)$ & 22,43 & 13,43 & 17,23 & 22,23 \\
\hline $\mathrm{FDAI}^{1}(I A D F)$ & 11,35 & 7,91 & 10,93 & 9,29 \\
\hline Lignina $^{1}$ (Lignin) & 3,35 & 3,09 & 3,98 & 3,69 \\
\hline Lignina/FDN ${ }^{1}$ (Lignin/NDF) & 8,06 & 11,50 & 12,79 & 9,77 \\
\hline Cafeína $^{1}$ (Caffeine) & 0,279 & 0,233 & 0,307 & 0,215 \\
\hline $\mathrm{PFT}^{1}(T P F)$ & 0,546 & 0,319 & 0,557 & 0,333 \\
\hline
\end{tabular}

1 Porcentagem da MS (\% of DM).

2 Porcentagem do nitrogênio total (\% of total nitrogen). 
Os dados obtidos foram submetidos à análise de variância e ao teste de média (Tukey) utilizando-se o programa SAEG, versão 7.0. (UFV, 1997a), a 5\% de significância.

\section{Resultados e Discussão}

Os consumos de MS (em kg/dia, \% PV e g/ $\mathrm{kg}^{0,75}$ ), de $\mathrm{MO}$ e CT não diferiram $(\mathrm{P}>0,05)$ entre as dietas experimentais (Tabela 4), o que está de acordo com as observações de Costa et al. (2005), confirmando a necessidade de maior participação de concentrado $(60 \%$ base da MS) em dietas à base de cana-de-açúcar para vacas leiteiras de alta produção como forma de compensar a limitação de consumo imposta pela parede celular da cana-de-açúcar.

Pesquisadores têm observado reduções no consumo de MS quando a polpa e a casca de café foram incluídas na dieta de ruminantes (Cabezas et al., 1976; Vargas et al., 1982; Rocha et al., 2004a) e que estas alterações estariam associadas à presença de compostos fenólicos e cafeína (RamirezMartine, 1988). Braham et al. (1973) sugeriram que a cafeína seria uma das possíveis causas da diminuição do consumo de alimentos e do aumento das concentrações de ácidos graxos livres no plasma, podendo reduzir o apetite e, conse- qüentemente, diminuir a ingestão de alimentos. Todavia, em vários estudos realizados com bovinos de corte no Brasil (Barcelos et al., 1997a; Barcelos et al., 1997b; Ribeiro Filho, 1998; Vilela, 1999) e com vacas em lactação (Barcelos et al., 1995; Souza et al., 2005), não foram registradas reduções no consumo de MS, o que pôde ser confirmado neste trabalho.

Apesar do aumento do teor de FDN da dieta de 26,87 para $37,76 \%$, na MS, quando $50 \%$ do milho foi substituído por casca de soja (20\% na dieta total), o consumo de MS não foi afetado $(\mathrm{P}>0,05)$. Resultados semelhantes para o consumo de MS têm sido observados em diversos trabalhos com vacas lactantes nos quais a casca de soja substituiu o milho em níveis de 15 a 48\% na MS total da dieta, porém, utilizando silagem de milho, silagem de alfafa, feno de alfafa ou feno de gramíneas como volumoso exclusivo (Ipharraguerre \& Clark, 2003).

Essas observações evidenciam que a utilização do teor de FDN como preditor único do consumo de MS parece ser inadequada (Vazques \& Smith 2000). Fatores como o conteúdo de lignina, a composição dos carboidratos estruturais, a taxa e a extensão da digestão da parede celular, o tamanho e a densidade de partículas devem ser considerados na avaliação do consumo de MS, principalmente quando se

Tabela 4 - Consumos diários de nutrientes das dietas experimentais Table 4 - Daily intakes of nutrients in the experimental diets

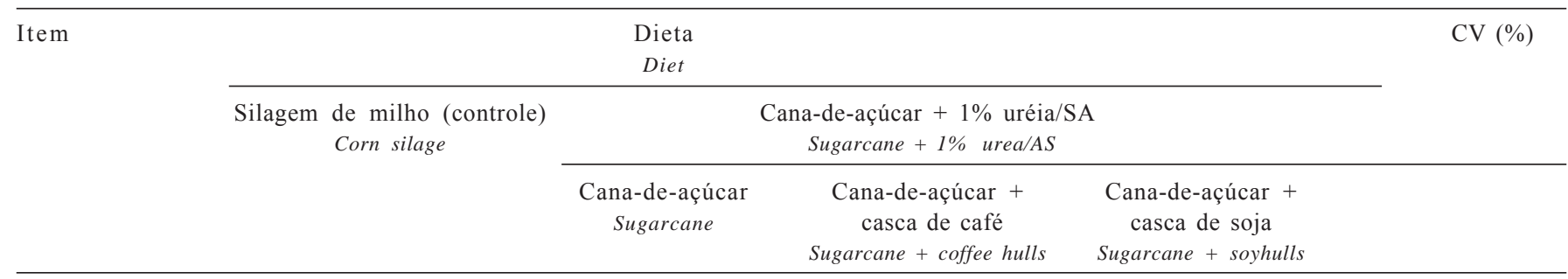

Consumo (kg/dia) (Intake, $\mathrm{kg} /$ day)

\begin{tabular}{|c|c|c|c|c|c|}
\hline MS (DM) & 18,35 & 20,07 & 18,83 & 20,29 & 10,45 \\
\hline MO $(O M)$ & 17,27 & 18,76 & 17,96 & 19,06 & 9,87 \\
\hline $\mathrm{PB}(C P)$ & $2,54 \mathrm{~b}$ & $2,81 \mathrm{ab}$ & $2,65 \mathrm{ab}$ & $2,86 \mathrm{a}$ & 8,79 \\
\hline $\mathrm{EE}(E E)$ & $0,42 \mathrm{a}$ & $0,41 \mathrm{a}$ & $0,34 b$ & $0,42 \mathrm{a}$ & 13,52 \\
\hline $\mathrm{CT}(\mathrm{TC})$ & 14,37 & 15,92 & 14,96 & 16,05 & 19,16 \\
\hline FDN (NDF) & $7,16 \mathrm{a}$ & $4,99 \mathrm{~b}$ & $5,35 b$ & $7,26 \mathrm{a}$ & 16,39 \\
\hline $\mathrm{CNF}(N C F)$ & $7,53 \mathrm{c}$ & $11,53 \mathrm{a}$ & $10,17 b$ & $9,40 \mathrm{~b}$ & 9,74 \\
\hline Cafeína $^{1}$ (Caffeine) & $51,66 \mathrm{ab}$ & $47,69 \mathrm{bc}$ & $56,61 \mathrm{a}$ & $42,71 \mathrm{c}$ & 13,49 \\
\hline $\mathrm{PFT}^{2}(T P F)$ & $96,17 \mathrm{a}$ & $62,45 b$ & $104,38 \mathrm{a}$ & $70,38 b$ & 14,90 \\
\hline NDTobs $^{3}$ (TDNobs) & $11,90 \mathrm{~b}$ & $14,29 \mathrm{a}$ & $12,08 b$ & $13,58 \mathrm{ab}$ & 13,55 \\
\hline & \multicolumn{5}{|c|}{ Consumo ( $\%$ do PV) (Intake, \% BW) } \\
\hline $\mathrm{MS}(D M)$ & 3,20 & 3,42 & 3,29 & 3,50 & 10,51 \\
\hline \multirow[t]{2}{*}{ FDN $(N D F)$} & $1,24 \mathrm{a}$ & $0,85 b$ & $0,94 b$ & $1,25 \mathrm{a}$ & 16,92 \\
\hline & \multicolumn{5}{|c|}{ Consumo $\left(\mathrm{g} / \mathrm{kg}^{0,75}\right)$ (Intake, $\left.\mathrm{g} / \mathrm{kg}^{0.75}\right)$} \\
\hline MS (DM) & 156,26 & 168,09 & 160,69 & 171,53 & 10,44 \\
\hline
\end{tabular}


utilizam diferentes fontes de FDN (Mertens, 1987; Allen, 1996; Allen, 2000). Desse modo, a manutenção do consumo de MS da dieta com cana-de-açúcar com a inclusão de $20 \%$ de casca de soja pode ser explicada pelo efeito positivo da elevada taxa de digestão da FDN, do pequeno tamanho e da alta capacidade de hidratação da partícula da casca de soja na taxa de passagem da FDN pelo trato gastroinestinal e, conseqüentemente, na ingestão de MS (Ipharraguerre \& Clark, 2003).

Preston (1977) sugeriu que a utilização de cana-deaçúcar corrigida com solução de uréia misturada a alimentos protéicos ricos em urease, como os subprodutos da soja, pode comprometer o consumo por reduzir a palatabilidade da dieta, em virtude da transformação de uréia em amônia e $\mathrm{CO}_{2}$ pela enzima urease (Coelho da Silva \& Leão, 1979). De fato, observou-se durante o experimento um odor característico de amônia na dieta total algumas horas após a mistura e nas sobras das vacas alimentadas com a dieta à base de cana-de-açúcar e com casca de soja. Todavia, a redução da aceitação da dieta somente ocorreu nos primeiros dias de adaptação e foi aparentemente restabelecida logo após. A atividade ureática da casca de soja utilizada foi de 0,46 e manteve-se abaixo do limite de 0,60 estabelecido pela legislação brasileira (SINDIRAÇÕES, 1998).

Os consumos de FDN (em kg/dia e \% do PV) foram menores $(\mathrm{P}<0,05)$ para as dietas à base de cana-de-açúcar, com $0 \%$ de substituição do milho e com $25 \%$ de substituição do milho por casca de café. Contudo, o mesmo não ocorreu para dieta com casca de soja, que não diferiu $(\mathrm{P}>0,05)$ da dieta à base de silagem de milho, provavelmente em virtude de diferenças quantitativas dos constituintes da fração fibrosa entre as dietas.

A maior participação de lignina na FDN das dietas à base de cana-de-açúcar sem e com substituição do milho por casca de café contribuiu para redução do consumo, em decorrência do efeito negativo da lignina na extensão e principalmente na taxa de digestão da FDN, que aumenta o tempo de retenção no retículo-rúmen e, conseqüentemente, reduz o consumo de FDN (Jung \& Allen, 1995).

A baixa proporção de ácidos ferúlico e p-cumárico, principais monômeros envolvidos na ligação da lignina com hemicelulose (Miron et al., 2001), associada à menor razão lignina/FDN da casca de soja em relação à silagem de milho, permitiu compensar o efeito negativo da cana-de-açúcar no consumo de FDN da dieta com casca de soja, o que explica a semelhança no consumo de FDN das dietas à base de silagem de milho e com casca de soja.

Os consumos de FDN, em \% do peso corporal, das dietas silagem de milho e cana-de-açúcar com casca de soja, estão de acordo com o valor observado por Mertens (1985), de $1,25 \%$ ( $\pm 0,1 \%$, que permite maximizar a ingestão de MS e energia de vacas em lactação. Contudo, o mesmo não ocorreu para as dietas à base de cana-de-açúcar com $0 \mathrm{e}$ $25 \%$ de substituição do milho pela casca de café, o que confirma os resultados obtidos por Magalhães et al. (2004), Souza (2003), Costa et al. (2005) e Mendonça et al. (2004). A maior relação lignina/FDN nessas dietas pode explicar os resultados, em razão do efeito negativo da lignina no consumo de FDN.

Os consumos de cafeína e polifenóis totais foram afetados pelas dietas, pois os maiores $(\mathrm{P}<0,05)$ valores foram obtidos com as dietas à base de silagem de milho e à base de cana-de-açúcar com casca de soja, que não diferiram $(\mathrm{P}>0,05)$ entre si. Esses resultados podem ser atribuídos ao maior teor de cafeína e polifenóis totais da silagem de milho em relação à cana-de-açúcar e da casca de café em relação ao milho.

Os teores dietéticos de cafeína e os valores de consumo de cafeína (9,00 e 9,87 g), expressos em g/100 kg de PV, obtidos para as dietas à silagem de milho e cana-de-açúcar com $25 \%$ de substituição do milho por casca de café superaram os níveis máximos toleráveis por ruminantes em crescimento (4,5 g de cafeína/100 kg de PV), mas não afetaram o consumo de MS (Vargas et al., 1982). Contrariamente, os teores dietéticos de polifenóis totais e o consumo de polifenóis $(16,77$ e 18,24 g/100 kg de PV) obtidos com essas dietas foram inferiores aos níveis máximos toleráveis por ruminantes em crescimento, de $28 \mathrm{~g}$ de PFT/100 kg de PV (Vargas et al., 1982).

Apesar das diferenças $(\mathrm{P}<0,05)$ no consumo de $\mathrm{PB}$ e $\mathrm{NDT}_{\text {obs }}$ entre as dietas, o consumo desses nutrientes foi suficiente para atender às exigências em proteína $(2,60 \mathrm{~kg} /$ dia de PB) e energia (10,58 kg/dia de NDT) descritas pelo NRC (2001) para vacas lactantes com $580 \mathrm{~kg}$ de PV, com 30 semanas de lactação produzindo $20 \mathrm{~kg} /$ dia de leite (com 3,5\% de gordura) e com ganho de peso de $0,50 \mathrm{~kg} / \mathrm{dia}$. Pequeno déficit de $0,06 \mathrm{~kg} / \mathrm{dia}$ de $\mathrm{PB}$ foi observado para a dieta à base de cana-de-açúcar sem substituição do milho do concentrado, mas esse déficit representou apenas $2,3 \%$ da exigência.

Como demonstrado na Tabela 5, não foram verificadas diferenças $(\mathrm{P}>0,05)$ entre as dietas quanto aos coeficientes de digestibilidade de MS, MO, PB, EE, CT e CNF e ao teor de NDTobs. Resultados semelhantes para as digestibilidades aparentes de MS, MO, EE e CT de dietas à base de cana-deaçúcar em relação a dietas à base de silagem de milho para vacas lactantes têm sido relatados na literatura (Magalhães et al., 2004; Souza, 2003; Costa etal., 2005; Mendonça etal., 2004).

A manutenção do coeficiente de digestibilidade da MS e MO de dietas para vacas lactantes quando o milho é substi- 
tuído por casca de soja foi observada também em outros trabalhos (Cunningham et al., 1993; Ipharraguerre et al., 2002b) e pode ser explicada pelas características qualitativas da fibra e pela quantidade e forma física da casca de soja, que permitem aumentar a digestão de fibra e, ao mesmo tempo, a taxa de passagem ruminal, como um processo de compensação (Ipharraguerre \& Clark, 2003), uma vez que a digestão é o resultado da interação entre as taxas de digestão e de permanência da digesta nos locais de digestão (Van Soest, 1994).

Embora o coeficiente de digestibilidade da $\mathrm{PB}$ não tenha diferido $(\mathrm{P}>0,05)$ entre as dietas à base de cana-deaçúcar sem e com casca de café, observou-se tendência de redução $(\mathrm{P}=0,1363)$ desse coeficiente. Reduções no coeficiente de digestibilidade da PB foram observadas em dietas para vacas lactantes com substituição do milho do concentrado por casca de café e podem ser atribuídas à maior proporção de compostos nitrogenados insolúveis em detergente ácido (NIDA) da casca de café (Souza et al., 2005; Rocha et al., 2004b). Os compostos nitrogenados em forma de NIDA são resistentes e praticamente indigestíveis no rúmen e geralmente estão associados à lignina e a outros compostos de difícil degradação (Licitra et al., 1996). Além disso, o alto teor de PFT na casca de café pode ter contribuído para a redução do coeficiente de digestibilidade da PB (Ribeiro Filho, 1998). Os polifenóis se ligam a proteínas impedindo o contato com enzimas proteolíticas e reduzindo a digestão ao longo do trato digestivo (Van Soest, 1994).

O coeficiente de digestibilidade da FDN foi maior $(\mathrm{P}<0,05)$ para a dieta à base de silagem de milho em relação às dietas à base de cana-de-açúcar sem e com casca de café, porém, não diferiu $(\mathrm{P}>0,05)$ do obtido com a dieta com casca de soja. Entre as dietas à base de cana-de-açúcar o coeficiente de digestibilidade reduziu $(\mathrm{P}<0,05)$ quando $25 \%$ milho foi substituído pela casca de café, enquanto, naquela com $50 \%$ de substituição do milho pela casca de soja, embora não tenha sido alterado $(\mathrm{P}>0,05)$, o coeficiente de digestibilidade da FDN apresentou tendência de aumento $(\mathrm{P}=0,29)$.

Reduções no coeficiente de digestibilidade da FDN quando a silagem de milho é substituída pela cana-deaçúcar são atribuídas a diferenças quantitativas entre os constituintes da parede celular da silagem de milho e da cana-de-açúcar (Magalhães et al., 2004; Souza, 2003; Costa et al., 2005; Mendonça et al., 2004). De fato, como demonstrados na Tabela 2, houve maior participação de lignina na FDN da cana-de-açúcar $(12,62 \%$ da FDN) em relação à silagem de milho (7,70\% da FDN), o que provavelmente contribuiu para a redução do coeficiente de digestibilidade da FDN, uma vez que a lignina é o principal componente da parede celular limitante da digestão dos carboidratos estruturais no rúmen (Weiss et al., 1992; Van Soest, 1994; Jung \& Allen, 1995). A maior participação de concentrado nas dietas à base de cana-de-açúcar $(60 \%$, na MS) não foi suficiente para compensar a menor digestibilidade da FDN da cana-de-açúcar em relação à silagem de milho.

A mesma explicação pode ser atribuída à redução do coeficiente de digestibilidade da FDN quando o milho da dieta à base de cana-de-açúcar foi substituído pela casca de café (Souza et al., 2005; Rocha et al., 2004b), uma vez que a participação da lignina na fração da FDN da casca de café $(18,77 \%$ da FDN) é superior à do milho ( $8,97 \%$ da FDN).

O aumento do coeficiente de digestibilidade da FDN com a substituição do milho pela casca de soja pode estar associado à elevada taxa de digestão da FDN da casca de

Tabela 5 - Coeficientes de digestibilidade aparente dos nutrientes e teores de NDT observados (NDTobs) das dietas experimentais Table 5 - Apparent digestibility of nutrients and observed TDN (TDNobs) in the experimental diets

\begin{tabular}{|c|c|c|c|c|c|}
\hline \multirow[t]{3}{*}{ Item } & \multicolumn{4}{|c|}{$\begin{array}{l}\text { Dieta } \\
\text { Diet }\end{array}$} & \multirow[t]{3}{*}{ CV (\%) } \\
\hline & \multirow[t]{2}{*}{$\begin{array}{l}\text { Silagem de milho (controle) } \\
\text { Corn silage }\end{array}$} & \multicolumn{3}{|c|}{$\begin{array}{c}\text { Cana-de-açúcar }+1 \% \text { uréia/SA } \\
\text { Sugarcane }+1 \% \text { urea/AS }\end{array}$} & \\
\hline & & $\begin{array}{l}\text { Cana-de-açúcar } \\
\text { Sugarcane }\end{array}$ & $\begin{array}{c}\text { Cana-de-açúcar }+ \\
\text { casca de café } \\
\text { Sugarcane }+ \text { coffee hulls }\end{array}$ & $\begin{array}{c}\text { Cana-de-açúcar }+ \\
\text { casca de soja } \\
\text { Sugarcane }+ \text { soyhulls }\end{array}$ & \\
\hline MO (OM) & 63,86 & 68,86 & 61,83 & 64,07 & 16,07 \\
\hline $\mathrm{PB}(C P)$ & 71,42 & 68,56 & 59,34 & 63,86 & 19,32 \\
\hline $\mathrm{EE}(E E)$ & 64,91 & 74,57 & 68,82 & 75,03 & 19,28 \\
\hline CT (TC) & 63,66 & 69,91 & 62,44 & 65,24 & 14,24 \\
\hline FDN (NDF) & $46,10 \mathrm{a}$ & $30,37 b$ & $18,21 \mathrm{c}$ & $37,55 \mathrm{ab}$ & 29,00 \\
\hline $\mathrm{CNF}(\mathrm{NCF})$ & 82,77 & 87,83 & 88,49 & 89,01 & 13,68 \\
\hline
\end{tabular}


soja (Titgemeyer, 2000), com a redução do efeito negativo do milho sobre a digestão da fibra (Nakamura \& Owen, 1989) ou ambos os fatores (Titgemeyer, 2000). No entanto, os mecanismos pelos quais a substituição do milho pela casca de soja resulta em efeito positivo da digestão da fibra ainda não estão totalmente elucidados, mas aparentemente não se relacionam à melhoria do $\mathrm{pH}$ do ambiente ruminal (Ipparraguerre \& Clark, 2003).

Como consta na Tabela 6 , não houve diferença $(\mathrm{P}>0,05)$ entre as dietas para a produção de leite, corrigida ou não para 3,5\% de gordura, a variação diária de peso, os níveis plasmáticos de $\mathrm{AGNE}$, os teores de $\mathrm{PB}$, gordura, extratos secos totais no leite e as produções diárias de $\mathrm{PB}$, gordura, lactose, extratos secos totais e extratos secos desengordurados. Em pesquisas utilizando dietas com cana-de-açúcar para vacas produzindo $20 \mathrm{~kg} /$ dia de leite com $40 \%$ (Magalhães et al., 2004; Souza, 2003; Costa et al., 2005; Mendonça et al., 2004) e 50\% (Costa et al., 2005; Mendonça et al., 2004) de concentrado, na MS, têm-se observado reduções na PL e na PLC em relação às dietas contendo silagem de milho e $40 \%$ concentrado, com variações negativas no peso das vacas, sugerindo que a utilização de cana-de-açúcar com esses níveis de concentrado promove mobilização de reservas corporais com potencial para comprometer a eficiência reprodutiva, sendo o baixo consumo de MS o principal fator limitante.

Tabela 6 - Produção diária de leite corrigida (PLC) ou não (PL) para 3,5\% de gordura (PLC), variação diária de peso (VP), níveis plasmáticos de ácidos graxos não-esterificados (AGNE), eficiência da PLC, teores no leite e produção diária de PB, gordura, lactose, extrato seco total (EST) e extrato seco desengordurado (ESD) obtidos com as dietas experimentais

Table 6 - Milk production (MP), 3.5\% fat-corrected milk (FCM), body weight change (BWC), plasma non-esterified fatty acids (NEFA), efficiency of FCM, milk content and yiled of CP, fat (F), lactose (LA), total solid (TS) and solids non-fat solid (SNF) of the experimental diets

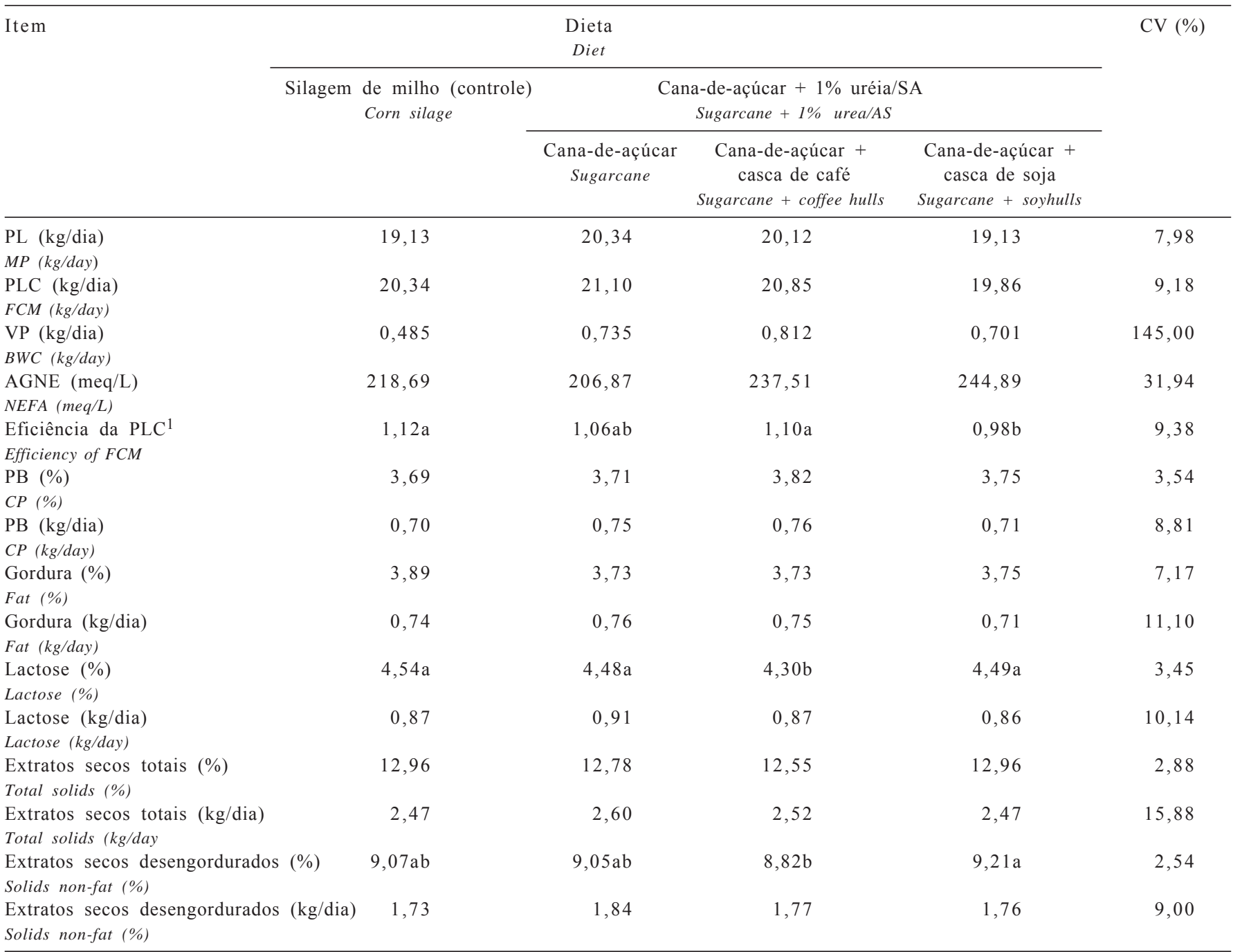

Médias seguidas de mesma letra na linha não diferem $(P>0,05)$ pelo teste Tukey.

Means followed by same letters in the row are not different $(P>0.05)$ by Tukey test.

${ }^{1}$ Eficiência $=$ PLC/Consumo de MS total da dieta $($ Efficiency $=$ FCM/DMI). 
No entanto, uma vez que neste trabalho o consumo de MS não foi afetado pelas dietas, apesar do menor $(\mathrm{P}<0,05)$ consumo de NDT da dieta à base de silagem de milho (controle) em relação à dieta à base de cana-deaçúcar, a ingestão desses nutrientes ainda foi suficiente para atender às exigências dos animais, o que explica a ausência de diferenças $(\mathrm{P}>0,05)$ na produção de leite e na variação diária de peso.

Essas observações confirmam os resultados obtidos por Costa et al. (2005), que não verificaram reduções na produção de leite corrigida ou não para 3,5\% de gordura ao compararem uma dieta com silagem de milho e $40 \%$ de concentrado e outra com cana-de-açúcar e $60 \%$ de concentrado (base da MS). Assim, para manutenção do desempenho produtivo, confirma-se a necessidade de maior participação de concentrado $(60 \%)$ em dietas à base de canade-açúcar em relação às dietas com silagem de milho contendo $40 \%$ de concentrado. Ressalta-se que o teor médio de PB dos concentrados das dietas à base de cana-de-açúcar ( $15,65 \%$, com base na MS) foi menor que o da dieta com silagem de milho $(24,00 \%$, base da MS), o que pode conferir maior benefício econômico da cana-de-açúcar.

Embora o consumo de NDT tenha sido menor $(\mathrm{P}<0,05)$ com a substituição de $25 \%$ do milho pela casca de café, esse consumo ainda foi suficiente para atender às exigências dos animais, o que também explica a ausência de diferenças $(\mathrm{P}>0,05)$ na produção de leite corrigida ou não para 3,5\% de gordura e na variação diária de peso.

Ausências de respostas na produção de leite também foram relatadas em estudos nos quais o milho foi substituído por casca de soja (emníveis de até $40 \%$ de inclusão na MS total) em dietas para vacas lactantes, porém utilizando silagem de milho, silagem de alfafa, feno de alfafa ou feno de gramíneas como volumoso exclusivo (Cunningham et al., 1993; Ipharraguerre et al., 2002a). A manutenção do consumo de PB e NDT quando o milho foi substituído pela casca de soja nas dietas à base de cana-de-açúcar justifica a ausência de resposta na produção de leite. Apesar da grande amplitude entre médias para variação de peso, não houve diferença $(\mathrm{P}>0,05)$ entre as dietas, em decorrência do alto coeficiente de variação, verificado também em outros trabalhos (Magalhães et al., 2004; Souza, 2003; Costa et al., 2005; Mendonça et al., 2004). Duas razões relacionadas à natureza dos ensaios rotativos explicam esta alta variação: os animais não são pesados em jejum, ocorrendo influência do efeito de enchimento do trato gastrintestinal no peso corporal; e, principalmente, o período de avaliação foi insuficiente para avaliar variáveis relacionadas à variação ou ao ganho de peso.

Todavia, a variação de peso das vacas alimentadas com a dieta à base de silagem de milho ficou próxima ao valor utilizado no cálculo das exigências nutricionais $(0,50 \mathrm{~kg} /$ dia), enquanto, nas vacas alimentadas com as dietas à base de cana-de-açúcar, as variações de peso foram maiores, em razão do maior consumo de NDT em relação às exigências preditas pelo NRC (2001). O aparente direcionamento da energia para ganho de peso corporal pode ser atribuído a dois fatores: o consumo ad libitum das dietas experimentais; e o estádio de lactação das vacas (205 dias de lactação, em média), caracterizado pelo restabelecimento das reservas corporais e pela elevada ingestão de MS (NRC, 2001).

Determinações dos níveis plasmáticos de AGNE permitem avaliar com maior precisão a ocorrência e o grau de mobilização de reservas corporais de vacas em lactação (Jonhson \& Peters, 1993; Ingvartsen \& Andersen, 2000), o que pode ser comprovado pelo menor coeficiente de variação dos valores de AGNE em relação à variação de peso. Portanto, constituem uma valiosa ferramenta de análise em delineamentos experimentais de diversas naturezas, principalmente os rotativos. O valor médio de AGNE (226,9 meq/L) das dietas indica baixo nível de mobilização de lipídios e está na faixa observada de 100,5 a 244,5 meq/L para vacas de alta produção no terço médio de lactação (Ingvartsen \& Andersen, 2000; Rennó Neto, 2004).

Redução nos teores de PB do leite quando o milho é substituído por casca de soja tem sido descrita na literatura (Nakamura \& Owen, 1989; Mansfield \& Stern, 1994). Reduções na síntese e no fluxo de proteína microbiana para o intestino delgado, associadas à redução do fluxo de glicose para síntese de proteína nos tecidos da glândula mamária, podem estar relacionadas à dimiuição no teor de PB do leite quando o nível de casca de soja excede $30 \%$ da MS da dieta (Ipharraguerre \& Clark, 2003). Contudo, neste trabalho o nível de casca de soja foi menor ( $20 \%$ na MS da dieta), o que explica a ausência $(\mathrm{P}>0,05)$ de efeito no teor de proteína do leite quando o milho foi substituído pela casca de soja.

\section{Conclusões}

Vacas leiteiras com produção de leite de $20 \mathrm{~kg} /$ dia no terço médio de lactação podem ser alimentadas com dietas exclusivamente à base de cana-de-açúcar em substiuição a dietas com silagem de milho desde que a participação de concentrado seja de $60 \%$.

Níveis de 25 ou $50 \%$ de substituição do milho pela casca de café ou pela casca de soja em dietas à base de cana-deaçúcar para vacas com produção de $20 \mathrm{~kg}$ de leite/dia podem ser utilizados de acordo com a disponibilidade e a conveniência econômica. 


\section{Literatura Citada}

ALLEN, M.S. Physical constraints on voluntary intake of forages by ruminants. Journal of Animal Science, v.74, p.30633075, 1996.

ALLEN, M.S. Effects of diet on short-term regulation of feed intake by lactating dairy cattle. Journal of Dairy Science, v. 83 , p.1598-1624, 2000

ASSOCIATION OF OFFICIAL ANALYTICAL CHEMISTS - AOAC. Official methods of analysis. 15.ed. Washington. 1990. 1117p.

BARCELOS, A.F.; ANDRADE, I.F.; VON TIESENHAUSEN, I.M.E.V. et al. Aproveitamento da casca de café na alimentação de novilhos confinados - resultados do primeiro ano. Revista Brasileira de Zootecnia, v.26, n.6, p.1208-1214, 1997a.

BARCELOS, A.F.; ANDRADE, I.F.; von TIESENHAUSEN, I.M.E.V. et al. Aproveitamento da casca de café na alimentação de novilhos confinados - resultados do segundo ano. Revista Brasileira de Zootecnia, v.26, n.6, p.1215-1221, 1997b

BARCELOS, F.A.; SETTE, R.S.; ANDRADE, I.F. et al. Aproveitamento da casca de café na alimentação de vacas em lactação. Lavras: Centro Regional de Pesquisa do Sul de Minas, 1995. p.1-4. (Circular Técnica, 45).

BIONDI, P.; CAIELLI, E.L.; FREITAS, E.A.N. et al. Substituição parcial e total da silagem de milho por cana-de-açúcar como únicos volumosos para vacas em lactação. Boletim da Indústria Animal, v.35, n.1, p.45-55, 1978.

BLASI, D.A.; DROUILLARD, J.S.; TITGEMEYER, E.C. et al. Soybean hulls: composition anf feeding value for beef and dairy cattle. Manhattan: Kansas State University, 2000. MF-2438.

BOIN, C.; ALLEONI, G.F.; BIONDI, P. et al. Comparação entre silagens de milho e cana-de-açúcar na alimentação de ruminantes: 1. Efeito do nível de concentrado na produção de leite. In: REUNIÃO ANUAL DA SOCIEDADE BRASILEIRA DE ZOOTECNIA, 20., 1983, Pelotas. Anais... Pelotas: Sociedade Brasileira de Zootecnia, 1983a, p.84.

BRAHAM, J.E.; JARQUIN, R.; GONZÁLEZ, J.M. et al. Pulpa y pergamino de café. III. Utilización de la pulpa de café en forma de ensilaje. Archivos Latinoamericanos de Nutricion, v.23, p.379-388, 1973 .

BRESSAN, M.; VERNEQUE R.S.; MOREIRA, P. A pecuária de leite em Goiás. Juiz de Fora: Embrapa Gado de Leite, Goiânia: Sindileite/Faeg, 1999. 310p.

CABEZAS, M.T. Valor nutitivo de la pulpa de café para ganado de corte. Agricultura en El Salvador, v.15, n.3, p.25-39. 1976.

CASTRO, A.C.G.; CAMPOS, J.; HILL; J. et al. Cana-de-açúcar "vesus"silagem de milho na produção de leite. Revista Ceres, v. 14 , n. 80 , p. 203-223, 1967

COCHRAN, R.C.; ADAMS, D.C.; WALACE, J.D. et al. Predicting digestibility of different diets with internal markers: evaluation of four potencial markers. Journal of Animal Science, v.63, p.1476-1483, 1986.

COELHO DA SILVA, J.F.; LEÃO, M.I. Fundamentos da nutrição de ruminantes. Piracicaba: Livroceres, 1979. 380p.

CORREA, C.E.S; PEREIRA, M.N.; OLIVEIRA, S.G. et al. Performance of holstein cows fed sugarcane or corn silages of different grain testures. Scientia Agricola, v.60, n.4, p.621-529, 2003.

COSTA, M.G; CAMPOS, J.M.S.; VALADARES FILHO, S.C. et al. Desempenho produtivo de vacas leiteiras alimentadas com diferentes proporções de cana-de-açúcar e concentrado ou silagem de milho na dieta. Revista Brasileira de Zootecnia, v.34, n.6, p.2437-2445, 2005 (supl.).

CUNNINGHAM, K.D.; CECAVA, M.J.; JOHNSON, T.R. Nutrient digestion, nitrogen and amino acid flows in lactating cows feed soybean hulls in place of forage or concentrate. Journal of Dairy Science, v.76, p.3523-3535, 1993

FERREIRA, A.H. Eficiência de sistemas de produção de leite: uma aplicação da análise envoltória de dados na tomada de decisão. Viçosa, MG: Universidade Federal de Viçosa, 2002.
Dissertação (Mestrado em Economia Aplicada) - Universidade Federal de Viçosa, 2002.

HALL, M.B. Calculation of non-estructural carbohydrate content of feeds that contain non-protein nitrogen. Gainesville: University of Florida, 2000. P.A-25 (Bulletin, 339)

INTERNATIONAL DAIRY FEDERATION - IDF. Whole milk determination of milkfat, protein and lactose content. Guide fir the operation of mid-infra-red instuments. Bruxelas: 1996. 12p. (IDF Standard 141 B).

INGVARTSEN, K.L.; ANDERSEN, J.B. Integration of metabolism and intake regulation: a review focusing on periparturient animals. Journal of Dairy Science, v.83, p.1573-1597, 2000.

IPHARREGUERRE, I.R.; CLARK, J.H. Review: soyhulls for dairy cows. Journal of Dairy Science, v.86, n.4, p.1052-1073, 2003.

IPHARREGUERRE, I.R.; IPHARRAGUERRE, R.R.; CLARK, J.H. Performance of lactating dairy cows fed varing amounts of soyhulls as a replacement for corn grain. Journal of Dairy Science, v. 85, p.2905-2912, 2002a.

IPHARREGUERRE, I.R.; SHABI, Z.; CLARK, J.H. et al. Ruminal fermentation and nutrient digestion by dairy cows fed varing amounts of soyhulls as a replacement for corn grain. Journal of Dairy Science, v.85, p.2890-2904, 2002b.

JOHNSON, M.M.; PETERS, J.P. Technical note: an improved method to quantify nonesterified fatty acids in bovine plasma. Journal of Dairy Science, v.71, p.753-756, 1993.

JUNG, H.G.; ALLEN, S. Characteristics of plant cell walls affecting intake and digestibility of forages by ruminants. Journal of Animal Science, v.73, p.2774-2790, 1995

LICITRA, G.; HERNANDEZ, T.M.; van SOEST, P.J. Standardization of procedures for nitrogen fractionation of ruminant feeds. Animal Feed Science and Technology, v.57, n.4, p.347-358, 1996.

MAGALHÃES, A.L.R.; CAMPOS, J.M.S.; VALADARES FILHO, S.C. et al. Cana-de-açúcar em substituição à silagem de milho em dietas para vacas em lactação: desempenho e viabilidade econômica. Revista Brasileira de Zootecnia, v.33, n.5, p.1292-1302, 2004

MANSFIELD, H.R.; STERN, M.D. Effects of soybean hulss and lignosulfonate-treated soybean meal on ruminal fermentation in lactating dairy cows. Journal of Dairy Science, v.77, p.1070-1083, 1994

MENDONÇA, S.S.; CAMPOS, J.M.S.; VALADARES FILHO, S.C. et al. Consumo, produção e composição de leite, variáveis ruminais de vacas leiteiras alimentadas com dietas à base de cana-de-açúcar. Revista Brasileira de Zootecnia, v.33, n.2, p.481-492, 2004.

MERTENS, D.R. Factors influencing feed intake in lactating cows: From theory to application using neutral detergent fiber. In: GA NUTRITION CONFERENCE, 46., 1985, Athens. Proceedings... Athens: University of Georgia, 1985. p.1-18.

MERTENS, D.R. Predicting intake and digestibility using mathematical models of ruminal function. Journal of Dairy Science, v.64, p.1548-1558, 1987.

MIRON, J.; YOSEF, E.; BEM-GHEDALIA, D. Composition and in vitro digestibility of monossacharide constituents of selected byproduct feeds. Journal of Agriculture and Food Chemistry, v.49, p.2322-2326, 2001.

NAKAMURA, K.; OWEN, F.G. High amounts of soybean hulls for pelleted concentrate diets. Journal of Dairy Science, v.72, p.988, 1989

NATIONAL RESEARCH COUNCIL - NRC. Nutrient requirements of dairy cattle. 7.ed. Washington, D.C.: National Academic Press, 2001. 381p.

NAUFEL, F.; GOEDMAN, E.F.; GUARAGNA, R.N. et al. Estudo comparativo entre cana-de-açúcar e silagem de milho, sorgo e capim napier na alimentação de vacas leiteiras. Boletim da Indústria Animal, v.26, p.9-22, 1969.

NOGUEIRA FILHO, J.C.M.; LUCCI, C.S.; ROCHA, G.L. et al. Substituição parcial da silagem de sorgo por cana-de-açúcar como únicos volumosos para vacas em lactação. Boletim da Indústria Animal, v.34, n.1, p.75-84, 1977. 
PAIVA, J.A.J.; MOREIRA, H.A.; CRUZ, G.M. et al. Cana-de-açúcar associada à uréia/sulfato de amônio como volumoso exclusivo para vacas em lactação. Revista Brasileira de Zootecnia, v.20, n.1, p.90-99, 1991.

PRESTON, T.R. Nutritive Value of sugarcane for ruminants. Tropical Animal Production, v.2, p.125-142, 1977.

RAMIREZ-MARTINEZ, J.R. Phenolic compounds in coffee pulp: quantitative determination by hplc. Journal Science Food and Agriculture, v.43, p.135-144, 1988.

RENNÓ NETO, B.P. Influência da aplicação da somatrotropina bovina (rBST) na função hepática, renal e no lipidograma de bovinos da raça holandês em lactação. Pirassununga: Universidade de São Paulo, 2004. 115p. Dissertação de Mestrado - Universidade de São Paulo, 2004.

RIBEIRO FILHO, E. Degradabilidade "in situ” da matéria seca (MS), proteína bruta (PB), e fibra em detergente neutro (FDN) da casca de café (Coffea arábica, L.) e Desempenho de novilhos mestiços em fase de recria. Lavras: Universidade Federal de Lavras, 1998. 56p. Dissertação (Mestrado em Zootecnia) - Universidade Federal de Lavras, 1998.

ROCHA, F.C.; GARCIA, R.; FREITAS, A.W.P. et al. Casca de café em dietas de vacas em lactação: consumo, produção de leite e variação de peso. In: REUNIÃO ANUAL DA SOCIEDADE BRASILEIRA DE ZOOTECNIA, 41., 2004, Campo Grande. Anais... Campo Grande: Sociedade Brasileira de Zootecnia, 2004a (CD-ROM).

ROCHA, F.C.; GARCIA, R.; FREITAS, A.W.P. et al. Digestibilidade de dietas com diferentes níveis de casca de café na alimentação de vacas em lactação. In: REUNIÃO ANUAL DA SOCIEDADE BRASILEIRA DE ZOOTECNIA, 41., 2004, Campo Grande. Anais... Campo Grande: Sociedade Brasileira de Zootecnia, 2004b (CD-ROM).

SILVA, D.J.; QUEIROZ, A.C. Análise de alimentos: métodos químicos e biológicos. 3.ed. Viçosa, MG: Universidade Federal de Viçosa, 2002. 235p.

SINDIRAÇÕES - SINDICATO NACIONAL DA INDÚSTRIA DE ALIMENTAÇÃO ANIMAL (Ed.) Compêndio brasileiro de alimentação animal. São Paulo: SINDIRAÇÕES, 1998. (paginação descontínua).

SKLAN, D.; ASHKENAZI, R.; BRAUN, A. et al. Fatty acids, calcium soaps of fatty acids and cottonseeds fed to high yielding cows. Journal of Dairy Science, v.75, p.2463-2472, 1992.

SOUZA, A.L.; GARCIA, R.; VALADARES FILHO, S.C. et al. Casca de café em dietas de vacas em lactação: consumo, digestibilidade e produção de leite. Revista Brasileira de Zootecnia, v.34, n.6, p.2496-2504, 2005.

SOUZA, D.P. Desempenho, síntese de proteína microbiana e comportamento ingestivo de vacas leiteiras alimentadas com caroço de algodão em substituição à cana-de-açúcar corrigida. Viçosa, MG: Universidade Federal de Viçosa, 2003. 79 p. Dissertação (Mestrado em Zootecnia) - Universidade Federal de Viçosa, 2003.

TEIXEIRA, J.C. Café. In: SIMPÓSIO SOBRE NUTRIÇÃO DE BOVINOS, 6., 1995, Piracicaba. Anais...Piracicaba: Fundação de Estudos Agrários Luiz de Queiroz, 1995. p.123-152.
TITGEMEYER, E.C. Soy by-products as energy sources for beef and dairy cattle. In: DRACKLEY, J.K. (Ed.) Soy in animal nutrition. Savy: Feeding Animal Science, 2000. p.238-256.

UNIVERSIDADE FEDERAL DE VIÇOSA - UFV. SAEG - Sistema de análises estatísticas e genéticas. Versão 7.1. Viçosa, MG: 1997. 150p. (Manual do usuário)

VALADARES FILHO, S.C.; ROCHA JR., V.R.; CAPPELLE, E.R. Tabelas brasileiras de composição de alimentos para bovinos. Viçosa, MG: Universidade Federal de Viçosa, 2002. $297 p$.

VALLE, L.C.S; MOZZER, O.L.; NETO, J.L. et al. Níveis de concentrado para vacas em lactação em pastagens de capim elefante, no período seco. 1. Produção e composição do leite. In: REUNIÃO ANUAL DA SOCIEDADE BRASILEIRA DE ZOOTECNIA, 23., Campo Grande. Anais... Campo Grande: Sociedade Brasileira de Zootecnia, 1986. p.98.

VALVASORI, E.; LUCCI, C.S.L.; ARCARO, J.R.P. et al. Avaliação da cana-de-açúcar em substituição à silagem de milho para vacas leiteiras. Brazilian Journal Veterinary Research Animal Science, v.32, n.4, p.224-228, 1995.

Van SOEST, P.J. Nutritional ecology of the ruminants. 2.ed. Ithaca: Cornell University, 1994. 476p.

VARGAS, E.; CABEZAS, M.T.; MURILO, B. et al. Efecto de altos niveles de pulpa de café deshidratada sobre el crecimiento y adaptación de novillos jóvenes. Archivos Latinoamericanos de Nutrición, v.32, n.4, p.972-989, 1982.

VASQUEZ, O.P.; SMITH, T.R. Factors affecting pastures intake and total dry matter intake in grazing dairy cows. Journal of Dairy Science, v.83, n.10, p.2301-2309, 2000.

VILELA, F.G. Uso da casca de café melosa em diferentes níveis na alimentação de novilhos confinados. Lavras: Universidade Federal de Lavras, 1999. 46p. Dissertação (Mestrado em Zootecnia) - Universidade Federal de Lavras, 1999.

VILELA, M.S.; FERREIRA, M.A.; VÉRAS, A.S.C. et al. Avaliação de diferentes suplementos para vacas mestiças em lactação alimentadas com cana-de-açúcar: desempenho e digestibilidade. Revista Brasileira de Zootecnia, v.32, n.3, p.768-777, 2003.

WEISS, W.P. Energy prediction equations for ruminant feeds. In: CORNELL NUTRITION CONFERENCE FOR FEED MANUFACTURERS, 61., 1999, Ithaca. Proceedings... Ithaca: Cornell University, 1999. p.176-185.

WEISS, W.P.; CONRAD, H.R.; ST. PIERRE, N.R. A theoreticallybased model for predicting total digestible values of forages and concentrades. Animal Feed Science and Technology, v.39, p.95-110, 1992 .
Recebido: 20/09/05 Aprovado: 01/03/07 